Є.C. Сагун

Льотна академія національного авіаиійного університету, Кропивнищький

\title{
МУЛЬТИКРИТЕРІАЛЬНА ОПТИМІЗАЦІЯ ЯК ПІДХІД ДО ПЛАНУВАННЯ ЗАВАНТАЖЕННЯ ПОВІТРЯНОГО СУДНА
}

\begin{abstract}
Стаття присвячена висвітленню особливостей використання методу мультикритеріальной оптимізації та аналізу припущень перед створенням алгоритму планування та оптимізації завантаження повітряного судна. Використовується комбінація з декількох раніше вивчених методів для створення нової моделі оптимізації, яка складається з математичної моделі та евристичних тверджень на базі експертних систем. Така система надасть можливість сформувати нові критерії, за якими слід в подальшому організовувати та оформлювати вантажну документацію, запобігаючи впливу сформованих вільних місиь у вантажному відсіку на проміжних відрізках маршруту слідування повітряного судна. Було визначено, щзо задля реалізації мультикритеріального підходу до вирімення проблеми планування та оптимізації завантаження повітряного судна та прийняття рішень, заснованих на альтернативах, необхідно подальще впровадження алгоритму оптимізаиї в експертну систему, орієнтовану на правилах.
\end{abstract}

Ключові слова: повітряне судно, планування завантаження, мультикритеріальна оптимізація, иільова функиія, NP- складна задача, оптимізація часу завантаження.

\section{Вступ}

Постановка проблеми. Повітряні вантажні перевезення дозволяють будь якому за типом вантажу у надзвичайно короткі строки прибути до пункту призначення. Швидка доставка гарантує збереження усіх умов для збереження характеристик вантажів, таких як температурний режим для чутливих до температурних змін вантажів. Саме процес завантаження повітряного судна грає визначну роль у операційній діяльності авіакомпанії та впливає на усі операції та процеси всередині підприємства та між сторонніми організаціями або іншими зацікавленими особами. 3 настанням кожного наступного рейсу, персонал, який відповідає за перевезення вантажу стикається 3 декількома проблемами одночасно. Першою проблемою $є$ покращення оборотності повітряного судна. Наступним завданням має бути збереження своїх позицій на ринку вантажних перевезень в умовах його теперішньої перенасиченості, що призводить до зниження середнього коефіцієнту завантаження [1]. Ринок вантажних авіаційних перевезень $є$ значно складнішим аніж пасажирський через низку технологічних специфічних процедур, комбінації ваги та об'єму, інтеграційних або консолідаційних стратегій тощо [4; 12]. Тому, авіаперевізники змушені постійно зменшувати витрати на комерційне обслуговування ПС, вантажу, який воно транспортує, витрати на паливо а інше з метою збереження фінансових показників своєї операційної діяльності. Така ситуація змушує авіакомпанії звернути увагу саме на проблему планування та оптимізації завантаження ПС, що на даний момент $є$ одні- єю 3 найбільш досліджуваних аспектів, що пов'язують виробничі дослідження та комбінаторну оптимізацію. Оптимізація завантаження, дійсно, призводить до збільшення оборотності ПС, що в свою чергу приносить авіаперевізнику вагомий економічний ефект від операційної діяльності. Однак, теперішнє програмне забезпечення 3 планування завантаження та проаналізовані наукові досягнення iз даної проблематики не надають жодних конкретних варіантів рішень щодо вибору оптимальних методів планування завантаження у призмі мультикритеріальної оптимізації або евристики. Головним завданням даного дослідження є вибір оптимального за декількома критеріями рішення, яке прийматиметься в умовах системи штучного інтелекту на базі експертних систем.

Аналіз останніх досліджень і публікацій. Системно, дослідження проблеми оптимізації та планування завантаження можна розділити на декілька підтипів, в залежності від мети та об'єкту дослідження: Пакування в контейнери, Завантажування контейнерів, Розміщення речей по методу Рюкзака, та Розподілення вантажу відносно вантажного відсіку ПС.

Пакування в контейнери (Bin Packing Problem) - це проблема, яка стосується завантаження об'єктів різних за розмірами у заздалегідь визначену кількість однакових контейнерів у такий спосіб, щоб кількість використаних контейнерів була мінімальною. Ця задача також відома як NP- складна, тобто не детермінована або невизначена поліноміальна задача яка є складною для вирішення на практичному прикладі, особливо у багатовимірному випадку 
[8]. У деяких дослідженнях зазначається, що Проблема пакування у контейнери може бути одно, двох або трьохвимірною, а також мати однакові або різні за формою та розмірами контейнери за умовою [3].

Проблема завантажування в контейнери (Container Loading Problem) тісно пов'язана 3 попередньою проблемою пакування (Bin Packing Problem). Автори досліджень знаходяться у пошуку шляхів оптимізації просторового розміщення вантажу всередині контейнеру з метою максимізації використання ємності ПС та вартості використаного вантажу [2].

Вирішення проблеми розміщення вантажу відносно вантажного відсіку ПС сфокусоване на розташуванні контейнерів у такий спосіб, щоб центр тяжіння завантаженого літака був близьким до оптимального та відповідав зазначеним показникам із виробничих характеристик ПС. Позиція центру тяжіння впливає на показники безпеки та ефективності польоту. Навіть найменше відхилення від оптимального центру тяжіння може призвести до підвищення показників споживання палива [11]. Іншою групою проблем 3 планування завантаження $є$ Проблема розміщення по принципу методу Рюкзака (Knapsack Problem) [6]. Вирішення складається 3 обрання певної кількості об'єктів з визначеної групи, максимізуючи при цьому загальний показник прибутку від цих об'єктів, який випливає із суми індивідуального прибутку вибраних до завантаження об'єктів. Повинні бути задоволені обмеження суми мас усіх вибраних предметів, що не повинна перевищувати максимальне комерційне завантаження [7]. Іншим вирішенням проблем оптимізації завантаження $є$ математична оптимізація, або програмування [5]. Видозміненим математичним $є$ також дискретне програмування [10].

Метою статті $\epsilon$ висвітлення особливостей використання методу мультикритеріальної оптимізації та побудова алгоритму вирішення для проблеми планування та оптимізації завантаження ПС.

\section{Виклад основного матеріалу}

Цілочислове математичне програмування $є$ методом, який займає дуже багато часу та виробляє занадто багато варіантів можливих рішень. Евристичні методи ігнорують обмеження з балансування ПС. Тому, одним із способів для вирішення проблеми планування та оптимізації завантаження ПС було обрано скомбінувати декілька різних підходів для розробки нової моделі оптимізації з декількома критеріями. Така модель складається 3 формальної частини - безпосередньо математичної моделі та частини для прийняття рішень - пошуку доцільних альтернатив. Завдання дослідження частково нагадує динамічне впорядкування. Тож, умови стохастичного середовища, у якому формується процес заванта- ження змушують вдаватись до створення альтернативних методів, які базуються на експертних системaх, орієнтованих на правилах та з логічними функціями.

\section{Припущення щодо алгоритму планування завантаження}

1) На першому етапі визначимо які за типологією вантажі пакувати у контейнери;

2) Переконуємось, що усі контейнери є гомогенними (однорідними);

3) Контейнери не можна обертати;

4) Конкретний контейнер може бути розвантажений лише у випадку, коли піддон від іншого контейнеру, який знаходиться зверху також вивантажено заздалегідь;

5) Кожний рейс складається 3 двох або більше проміжних часток маршруту (лагів) на шляху до кінцевого пункту призначення;

6) Вантаж зберігається на складі та з метою подальшого завантаження переміщується на спеціальну платформу або рампу;

7) Повітряне судно може перевозити лише тип вантажу, який сумісний із характеристиками вантажного відсіку цього ПС;

8) Всередині контейнерів відсутне перекриття або інших перехрещень вантажу;

9) Вантаж повинен бути розміщений паралельно до країв стінок контейнеру;

10) Обраний конкретний вантаж має бути розміщений в межах одного контейнеру;

11) На проміжних частинах маршруту необхідно запобігти пере завантаженню вантажу.

У дослідженні розглядається випадок, у якому надається визначена кількість предметів вантажу, які мають бути перевезені з розрахункового аеропорту вильоту за трьома напрямками: А, В та С. Вантаж має свої характеристики, такі як:

- Розміри;

- Вага;

- Тип вантажу (згідно збірника IATA 3 небезпечних вантажів);

- Характеристики сумісності вантажу;

- Пункт призначення (від А до В, від А до С та iн.)

Автором розглядається лише вантажне повітряне судно із рампою, аніж з апарельним способом завантаження задля ще більш уточнених результатів дослідження.

Дана робота також передбачає декілька критеріїв сортування вантажу перед його завантаженням. Першим завданням є скомпонувати вантаж на якомога меншу кількість палетів або контейнерів. Наступним завданням є запобігання перемішуванню різних типів вантажу в одному й тому ж контейнері.

Окрім інформації по типу вантажу, надається додаткова інформація стосовно: 
- Пункту відправлення та призначення; IATA трьох літерний код аеропорту;

- Розрахунковий час прибуття за розкладом;

- Розрахунковий час відправлення.

Прямокутний контейнер характеризується глибиною, шириною та висотою, а також максимальним комерційним завантаженням. Вантаж характеризується також за розмірами (глибина, ширина, висота та вага), а також маршрут слідування (призначення).

\section{Формалізація проблеми}

Розглянемо вантажний відсік, в який повинні бути завантажені прямокутні контейнери. Цільова функція складатиметься із зменшення кількості пере завантажень контейнерів, в подальшому мінімізуючи загальний час, витрачений на хендлінгове обслуговування.

Таким чином, цільова функція полягає саме у зменшенні часу для завантаження за допомогою скорочення процесів пере завантаження. Формалізована модель включатиме наступні параметри:

Індекси математичної моделі:

$b$ - bin / контейнер ( $b=1$ до $n$ );

$t$ - time range / часовий відрізок $\left(t=1\right.$ до $\left.n_{s t}\right)$;

$s-$ stack/ штабель ( $s=1$ до $\left.n_{s t}\right)$.

Нехай, $X R_{c g}$ and $Y R_{c g}$ будуть $x$ - координатами та $y$ - координатами відносно центру тяжіння після завантаження ПС.

Вихідні параметри функиї:

$\delta x_{i}$ - повздовжнє відхилення фактичного центру маси від оптимального $i$ - контейнеру;

$\delta y_{i}$ - поперечне відхилення фактичного центру маси від оптимального $i$ - контейнеру [9];

$T_{\text {loadi }}$ - час завантаження $i$ контейнеру до ПС;

$T_{p}$ - час паркування ПС на пероні (год);

$P$ - пеня за паркування на пероні поза безплатними нормами /за год;

$w_{i}$ - вага $i$ - контейнеру;

$C$ - ємкість вантажного відсіку;

$n$ - кількість контейнерів (ціле число, $>0$ );

$n_{s t}-$ кількість штабелів (ціле число, $>0$ );

$N r$ - максимальна кількість часових відрізків, потрібних для пере завантаження;

Варіанти рішень в межах моделі:

$R_{b, s . t}=1$ випадок, коли контейнер $b$ з вантажем переміщують із одного штабелю $s$ у конкретний проміжок часу $t$;

$P_{b, s, t}=1$, коли контейнер $b$ з вантажем знову розміщують on the stack $s$ у конкретний проміжок часу $t$;
$M_{b, t}=1$ коли контейнер $b$ з вантажем виключений у конкретний проміжок часу $t$.

Цільова функція

Оскільки цільовою функцією є мінімізація часу завантаження визначеної кількості контейнерів 3 вантажем, то виглядати вона буде наступним чином:

$$
\min \sum_{i=1}^{n} T_{\text {load }_{i}} .
$$

В цьому конкретному випадку мінімізація часу завантаження означає зменшення кількості пере завантажень на проміжних частинах маршруту. Внесемо додатковий критерій до функції:

$$
\min \sum_{i=1}^{n} \operatorname{Pr}_{i} \cdot m N_{\text {rload }_{i}} \cdot X_{i_{(x, y, z .)}} .
$$

За умови, що:

$$
\begin{gathered}
X R_{c g} \rightarrow 0 ; \\
\delta x_{i} \geq 0 ; \forall_{i} \in\{1, \ldots n\} ; \\
Y R_{c g} \rightarrow 0 ; \\
\delta x_{i} \geq 0, \forall_{i} \in\{1, \ldots n\} ; \\
w_{i} \leq C, \forall_{i} \in\{1, \ldots n\} ; \\
\min \sum_{i=1}^{n} T_{\text {load }_{i}} \leq T_{p} ; \\
P \rightarrow \min , \forall_{i} \in\{1, \ldots n\},
\end{gathered}
$$

де $\operatorname{Pr}_{i}-$ пріоритетність $d t_{i}$ визначеного контейнеру згідно його пункту призначення;

$$
\begin{aligned}
& d t_{i}-\text { час доставки } i-\text { контейнеру } \operatorname{Pr}_{i}=1 / d t_{i} ; \\
& m N_{\text {rload }_{i}}-\text { мінімальна кількість перезаванта- }
\end{aligned}
$$
жень $i$ контейнеру;

$X i(x, y, z)$ змінні варіантів рішень.

Згідно цільової функції, обмеження поділяються на:

Обмеження з центрування: Обмеження (3), (4). Специфічні обмеження:

$$
\begin{gathered}
R_{b, s . t} \leq M_{b, t} \quad \forall_{b}, \forall_{s}, \forall_{t} ; \\
P_{b, s, t} \leq M_{b, t} \quad \forall_{b}, \forall_{s}, \forall_{t} ; \\
\sum_{b=1}^{C} M_{b, t} \leq 1 \quad \forall_{t} .
\end{gathered}
$$

Обмеження (9) означає, що не більш ніж один вантажний контейнер може бути переміщений протягом одного відрізку часу. Це обмеження, поєднане 3 обмеженнями (7) та (8), припускає, що вантажний контейнер який розміщений у певному штабелі має бути саме тим, який потрібно перемістити у певний момент у будь якому порядку. Обмеження (10) визначає, що контейнери повинні вивантажуватись 3 відсіку літака лише у визначеній послідовності (що залежить від загального маршруту слідування та його конкретної частини $i$ ). 


$$
\begin{gathered}
S=\frac{B}{8 \cdot b}, \sum_{t=1}^{N r} t \cdot T_{\text {load }_{i+1, t}} \geq 1+\sum_{t=1}^{N r} t \cdot T_{\text {load }_{i, t}}, \forall b \\
\text { from } 1 \text { to } b-1 .
\end{gathered}
$$

Мультикритеріальні завдання такого виду виникають, коли потрібно задовольнити декілька критеріїв цільової функції одночасно. На перший погляд, можливість оцінювання рішень за допомогою декількох різних критеріїв здається не зовсім природнім. Проте подібні завдання виникають у багатьох дослідженнях, тому доцільний компроміс рішень повинен бути знайдений.

Головною проблемою мультикритеріальної оптимізації $\epsilon$ неоднозначність вибору оптимальних рішень. Тому за оптимальне рішення може сприйматися одне 3 ефективних (Парето ефективних) варіантів.

Система, яка розробляється на базі декількох методів оптимізації має на меті запобігання процедури перезавантаження. Такий прототип експертної системи (ЕС) надасть змогу організувати документацію по центруванню та завантаженню літака таким чином, щоб запобігти впливу сформованих “вільних" місць у вантажному відсіку, які залишаються після першого циклу вивантажень на подальші показники балансування ПС.

\section{Висновки}

“Вузькі місця” у технологічних ланках існують на кожному кроці процедури планування завантаження. Та, в даному випадку автор звертає увагу саме на етап розподілення вантажу. Кінцевою метою подальшого алгоритму є можливість розміщення вантажу таким чином, щоб передбачити подальший його рух протягом маршруту задля запобігання процедурам вивантаження та перезавантаження. Велика кількість наукових робіт висвітлює вирішення проблеми оптимізації завантаження різними та подекуди навіть суперечливими методами, маючи на меті зменшити кошти на пальне або оптимізувати корисне використання ємності ПС. Дана робота має інше цільове призначення, а саме - планування переміщення вантажу всередині відсіку літака 3 метою пришвидшення хендлінгового процесу в умовах мультилагового маршруту.

Автором запропоновані додаткові обмеження, які повинні бути враховані для оптимальності плану завантаження ПС. Були введені нові критерії та припущення до моделі, проте досліджувана проблема все ще залишається NP-складною.

\section{Список літератури}

1. International Air Transport Association. Air Freight Market Analysis [Electronic resource] // Air Freight Market Analysis. - 2016. - Available at: https://www.iata.org/publications/economics/Reports/freight-monthly-analysis/freight-analysis-dec2018.pdf.

2. Bortfeldt A. A hybrid genetic algorithm for the container loading problem / A. Bortfeldt, H. Gehring // European Journal of Operational Research. - 2001. - № 131. - P. 143-161.

3. Dyckho H. A typology of cutting and packing problems / H. Dyckho // European Journal of Operational Research. 1990. - № 44. - P. 145-159.

4. Li Y. A Compromised large-scale neighbourhood search heuristic for capacitated air cargo loading planning / Y. Li, Y. Tao, F. Wang // European Journal of Operational Research. - 2009. - № 199(2). - P. 533-560.

5. Fok K. Optimizing air cargo load planning and analysis / K. Fok, A. Chun // Proceedings of the International Conference on Computing, Communications and Control Technologies, Austin, Texas, USA, 2004. - P. 6.

6. Kellerer H. Knapsack Problems / H. Keller, U. Pferschy, D. Pisinger. - London: Springer, 2004. - 546 p.

7. Martello S. Knapsack Problems: Algorithms and Computer Implementations / S. Martello, P. Toth. - USA: John Wiley \& Sons, 1990. -35 p.

8. Paquay C. Three dimensional Bin Packing Problem applied to air transport / C. Paquay, M. Schyns, S. Limbourg. Belgium: University of Liège, 2011. - P. 6.

9. Sahun Ye. Current status of aircraft load optimization problem / Ye. Sahun // Proceedings of the National Aviation University. - 2019. - № 1(78). - P. 35-39.

10. Suhl H. Uwe. Solving Airline fleet Scheduling Problems with Mixed - integer Programming / Uwe H. Suhl, Leena M. Suhl // Operational Research in Industry. - 1999. - № 7. - P. 135-156.

11. Trivella A. Bin-packing problems with load balancing and stability constraints / A. Trivella, D. Pisinger // INFORMS Transportation and Logistics Society. - Chicago, 26 July 2017. - P. 5.

12. Wang J.Y. An Application of a fuzzy knowledge system for air cargo overbooking under uncertain capacity $/$ J.Y. Wang, C.S. Kao // Computer \& Mathematics with Applications. - 2008. - № 56(10). - P. 2666-2675. 
Bidомості про автора:

Сагун Слизавета Сергї̈вна аспірант

Льотної академії національного

авіаційного університету,

Кропивницький, Україна

https://orcid.org/0000-0003-4837-4688
Information about the author:

Yelyzaveta Sahun

Doctoral Student

of Flight Academy

of the National Aviation University,

Kropyvnytsky, Ukraine

https://orcid.org/0000-0003-4837-4688

\title{
МУЛЬТИКРИТЕРИАЛЬНАЯ ОПТИМИЗАЦИЯ КАК ПОДХОД К ПЛАНИРОВАНИЮ ЗАГРУЗКИ ВОЗДУШНОГО СУДНА
}

\author{
Е.С. Сагун
}

Статья посвящена особенностям использования метода мультикритериальной оптимизации и разработке предварительного алгоритма решений в планировании и оптимизации загрузки воздушного судна. Решение проблемы оптимизаиии загрузки было разделено на несколько этапов в зависимости от иели и объекта исследования. В данной работе идет речь, в частности, о проблеме распределения груза. Огромное количество научных исследований предоставляют варианты решений проблемы оптимизации загрузки, преследуя цель оптимизачии расходов на топливо или полезного использования емкости воздушного судна. Однако данная работа имеет несколько иное иелевое предназначение, а именно - планирование перемещения груза внутри грузового отсека самолета с иелью ускорения процедур авиационного хендлинга в условиях мультилагового марирута. Используется комбиначия из нескольких ранее изученных методов для создания новой модели оптимизации, которая состоит из математической модели и эвристических утверждений. Такой подход предоставит возможность сформировать новые критерии, по которым следует в дальнейшем организовывать и оформлять грузовую документаџию, предотвращая при этом влияние сформированных свободных мест в грузовом отсеке ВС на промежуточных участках маршрута. Было определено, что для реализации мультикритериального подхода к решению проблемы планирования и оптимизачии загрузки воздушного судна необходимо дальнейшее внедрение алгоритма оптимизации в экспертную систему, ориентированную на правилах.

Ключевые слова: воздушное судно, планирование загрузки, мультикритериальная оптимизация, иелевая функция, $N P$ - сложная задача, оптимизация времени загрузки.

\section{MULTICRITERIA OPTIMIZATION \\ AS AN APPROACH OF AIRCRAFT LOAD PLANNING}

Ye. Sahun

The article is dedicated to highlight the specificities of multicriteria optimization methods utilization and building of suppositions towards decision making algorithm of aircraft load planning and optimization. The load optimization problem's solution was decomposed to a few stages according to their goals and research objects. The following work particularly deals with cargo assignment problem. A large amount of scientific works present the load optimization solutions with quite different and sometimes contradictory methods, aiming to cut fuel consumption or to improve the aircraft's capacity. Thus the current work has the different aim, but to plan the cargo's movement inside the aircraft cargo bay in order to speedup handling procedures in multi leg conditions. The work uses a combination of a few previously studied methods for creating a completely new optimization model that consists of mathematical model and heuristic approach based on the expert systems logic. Such approach will be able to implement new criterion, which are the fundamental for arranging and forming of the cargo documentation, avoiding the impact of appearing empty spaces in a cargo bay during multi leg flight. It was defined, that the implementation of optimization algorithm in a rule-based expert system is necessary for multicriteria approach integration in aircraft load planning and optimization solution. Such prototype of an ES would let the weight and balance sheet be arranged in a way to prevent an impact of formed "empty" space points trim and would not go beyond the required boundaries. The input parameters will be presented as a digital data, processing in real time, with the possibility of their correction and rewriting. The output parameters are reflected as graphics and numbers on a work screen in real time mode.

Keywords: aircraft, load planning, multicriteria optimization, objective function, NP- hard task, load time optimization. 